Article

\title{
Hydraulic Conductivity Characteristics of Desert Plant Organs: Coping with Drought Tolerance Strategy
}

\author{
Shanjia Li ${ }^{1,2, *(\mathbb{D})}$, Peixi Su ${ }^{2}$, Haina Zhang ${ }^{3,4}$, Zijuan Zhou ${ }^{2}$, Rui Shi ${ }^{2}$ and Wei Gou ${ }^{1}$ (D) \\ 1 School of Life Science and Engineering, Lanzhou University of Technology, Lanzhou 730050, China; \\ lsjlut@163.com \\ 2 Key Laboratory of Land Surface Process and Climate Change in Cold and Arid Regions, Northwest Institute \\ of Eco-Environment and Resources, Chinese Academy of Sciences, Lanzhou 730000, China; \\ supx@lzb.ac.cn (P.S.); zhouzzj@lzb.ac.cn (Z.Z.); $18634936969 @ 163 . c o m$ (R.S.) \\ 3 Research Center of Water Resources and Ecological Environment of Poyang Lake, the Ministry of Water \\ Resources of the People's Republic of China, Nanchang 330029, China; zhanghaina@nit.edu.cn \\ 4 School of Water Resources and Ecological Engineering, Nanchang Institute of Technology, \\ Nanchang 330099, China \\ * Correspondence: lishanjia@lut.edu.cn; Tel.: +86-931-297-6385
}

Received: 4 July 2018; Accepted: 1 August 2018; Published: 5 August 2018

\begin{abstract}
Plant hydraulic conductivity (K) refers to the rate of water flow $\left(\mathrm{kg} \mathrm{s}^{-1}\right)$ per unit pressure drop (MPa), which drives flow through the plant organ system. It is an important eco-physiology index for measuring plant water absorption and transport capacity. A field study was conducted in the arid region of the Heihe River Basin in northwestern China, plant hydraulic conductivity was measured by high-pressure flowmeter (HPFM) to investigate the characteristics of hydraulic conductivity of typical dominant desert plants (Reaumuria soongarica M., Nitraria sphaerocarpa M., and Sympegma regelii B.) and their relationship with functional traits of leaves, stems, and roots, and explaining their adaptation strategies to desert environment from the perspective of plant organs hydraulic conductivity. The results showed that the hydraulic conductivity of the leaves and stems of $R$. soongarica and $N$. sphaerocarpa $\left(\mathrm{K}_{\mathrm{LA}}\right.$, leaf hydraulic conductivity per unit leaf area; $\mathrm{K}_{\mathrm{LW}}$, leaf hydraulic conductivity per unit leaf weight; $\mathrm{K}_{\mathrm{SLA}}$, stem hydraulic conductivity per unit leaf area; $K_{\text {SLW }}$, stem hydraulic conductivity per unit leaf weight) were significantly lower than those of $S$. regelii, while their fine root $\left(\mathrm{K}_{\mathrm{RL}}\right.$, root hydraulic conductivity per unit leaf length; $\mathrm{K}_{\mathrm{RSA}}$, root hydraulic conductivity per unit root surface area) and whole root $\left(\mathrm{K}_{\mathrm{TRW}}\right.$, whole root hydraulic conductivity per unit root weight) of hydraulic conductivity were significantly higher than those of $S$. regelii. In addition, $\mathrm{K}_{\mathrm{LA}}$ and $\mathrm{K}_{\mathrm{LW}}, \mathrm{K}_{\mathrm{SLA}}$ and $\mathrm{K}_{\mathrm{SLW}}$, and $\mathrm{K}_{\mathrm{RL}}$ and $\mathrm{K}_{\mathrm{RSA}}$ in three desert plants all exhibited consistent trends. Correlation analysis illustrated that the hydraulic conductivity of leaves and stems had a significantly positive correlation, but they had no significant negative correlation with the specific leaf weight (SLW, specific leaf weight). The hydraulic conductivity of fine root weight $\left(\mathrm{K}_{\mathrm{RW}}\right.$, root hydraulic conductivity per unit root weight) and specific root surface area (SRSA, specific root surface area) showed significantly positive correlation $(r=0.727, P<0.05)$. The results demonstrated that the $R$. soongarica and N. sphaerocarpa preserved their water content through the strong leaf absorption capacity of soil water and the low water dispersion rates of leaves to adapt to the harsher arid habitat, which is more drought tolerant than $S$. regelii.
\end{abstract}

Keywords: desert plant; hydraulic conductivity; high-pressure flowmeter; plant functional traits; drought tolerance 


\section{Introduction}

Water is a limiting factor for survival and growth of desert plants [1]. The flow of water in the soil-plant-atmosphere continuum is a passive process driven by water potential differences and enabled by the continuity of the liquid phase of water between the soil and the leaf mesophyll [2]. To adapt to the arid environment, plants formed multiple morphologic and physiologic adaptation strategies to resist the drought stress environment of the outside world, including plant morphology and structure, growth rate, water use efficiency, antioxidant system, and developed root system [3]. Hydraulic architecture involves different morphologies, structures, and water transport and supply strategies formed by plants for adaption to survival and competition requirement in a particular environment. Research hydraulic architecture of plants can help us understand the characteristics of water physiological ecology and clarify the mechanism of drought resistance of plants. Plant hydraulic conductivity $(\mathrm{K})$ is one of the commonly and most importantly used eco-physiology parameters of hydraulic architecture characteristics for measuring water absorption and transmission, and refers to the ratio of water flow $\left(\mathrm{kg} \mathrm{s}^{-1}\right)$ per unit pressure drop $(\mathrm{MPa})$, which drives flow through the plant or plant organ systems, thus reflecting the water conveyance speed of plant organs [4]. Studies have shown that the roots and leaves hydraulic conductivity of wheat and soybean were decreased or lost under water stress, and Pinus tabulaeformis and Platycladus orientalis also showed the same trend [5-7]. Previous research regarding plant hydraulic architecture has mainly concentrated on trees and crops $[5,8,9]$, the economic importance of trees and crops had an impact on the number of studies addressing their hydraulic architecture; however, the water transport distance of shrubs is shorter than that of the trees and crops, and the branching system of shrubs is more complex, the hydraulic architecture of shrubs is of less concern. There have been many studies on the relationship between the functional traits and drought resistance characteristics of plant organs [10,11]. Zheng et al. [12] observed that the specific leaf weight (SLW) of trees, shrubs, and herbage exhibited an increasing trend with the aggravation of the arid climate from the south of the Qinling Mountain to the north of the Loess Plateau. With continuous drought, different functional types of plants will form thicker and smaller leaves, the dry matter content per unit leaf area will increase, and the plant specific leaf area (SLA) will increase. The analysis based on leaves characteristics of 2548 plants from 175 sampling points throughout the world, demonstrated that the SLW increased with the decrease of rainfall and the increase of light radiation [13]. In crops research, Li et al. [9] investigated the morphologies of the leaves of peanut varieties with different drought resistance, and the results demonstrated that the drought stress increased the SLW. These studies indicated that SLW is an important indicator for measuring the drought resistances of plants [14-16]. The root system is an organ that absorbs water from the soil and is the site where the plant initially perceives drought [8], and the morphology characteristics, such as root length (RL), specific root length (SRL), root surface area (RSA), specific root surface area (SRSA), and root diameter (RD), are important parameters affecting water and nutrients uptake of plants [17], which is closely related to the drought resistance of plants. Soil water stress forced the root diameter of Reaumuria soongarica seedlings to become smaller, the root volume decreased, and the specific surface area and specific root length increased [18]. Cortina et al. [19] held that the fine root was an important part of the root system of plants, with important physiological and ecological characteristics, and was very sensitive to the changes of water, thus many plants could adapt to drought stress by increasing both the numbers of fine roots and surface area.

In summary, the plant hydraulic conductivity and functional traits of the leaves, stems, and roots were associated with drought resistance, but there has been less research on the relationship among these trait parameters. Previous studies have pointed out that the hydraulic conductivity of the root system of maize was negatively correlated with the root diameter [8]. In addition, the hydraulic conductivity of the root system of the winter wheat was significantly positively correlated with the diameter of the central catheter of xylem, and it was significantly negatively correlated with both the root diameter and cortical thickness [5]. Under water stress, the factors leading to the decrease of the root radial flow conductance include the decrease of the diameter of the central catheter of 
the xylem of the root system, and the increase of the diameter of the root system and the cortical thickness [20]. The hydraulic conductivity of the xylem of Pinus tabulaeformis and Platycladus orientalis increased with the increase of the diameter of the functional xylem [7]. These studies were conducted in the branches or roots of trees and crops, and the relationship between the hydraulic conductivity of shrubs and various functional traits of drought resistances remains to be investigated. In this study, the typical dominant shrubs (R.soongarica, N.sphaerocarpa, S.regelii) under the natural conditions of the desert region were selected as the research subjects, and the hydraulic conductivity of leaves, stems, and roots were measured by a high-pressure flowmeter (HPFM), to explore the relationship between the hydraulic conductivity of these three shrubs and the functional traits of leaves, stems, and roots, indicating their adaptation strategy to the desert environments.

\section{Materials and Methods}

\subsection{Study Area, Species, and Sampling Method}

The study was conducted in arid land of the middle reaches of the Heihe River Basin in Gansu Province, China $\left(39^{\circ} 24^{\prime} \mathrm{N}, 100^{\circ} 07^{\prime} \mathrm{E}\right)$, and the central part of the Hexi Corridor, which is the extension zone of the southern part of the Badain Jaran Desert, with a temperate arid desert climate type. The average annual temperature was $7.6^{\circ} \mathrm{C}$ and the highest temperature was $39.1^{\circ} \mathrm{C}$. The minimum temperature was $-27{ }^{\circ} \mathrm{C}$, the annual accumulated temperature of greater than or equal to $10^{\circ} \mathrm{C}$ was $3088^{\circ} \mathrm{C}$, and the frost-free period was 165 days. The average annual rainfall was $117 \mathrm{~mm}$, the highest rainfall was $210.5 \mathrm{~mm}$, and the lowest rainfall was $82.9 \mathrm{~mm}$. The rainfall was concentrated between July and September, accounting for about $70 \%$ of annual rainfall. The annual potential evaporation was $2390 \mathrm{~mm}$, which was more than 20 times the precipitation (these data are the average of meteorological statistics from 1951 to 2010 in the weather station near the sampling point). Drought, high temperature, and wind were the major climatic characteristics [21]. The main desert plants included Reaumuria soongarica M., Nitraria sphaerocarpa M., and Sympegma regelii B. The soil was composed of the quaternary alluvial deposits, most of the ground contained gravel (Figures 1 and 2).

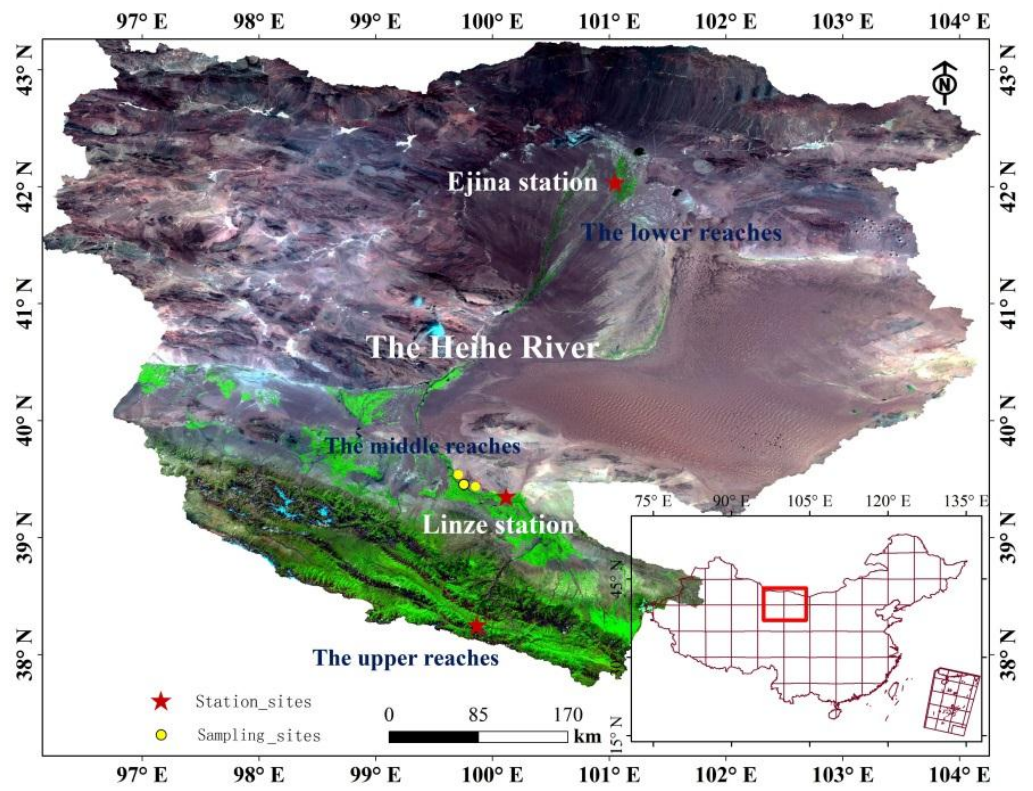

Figure 1. Geographical location of sampling sites in the study area of Heihe River Basin. The green areas signifies vegetation, the yellow spot signifies sampling sites, and the text describes the Heihe River Basin. 


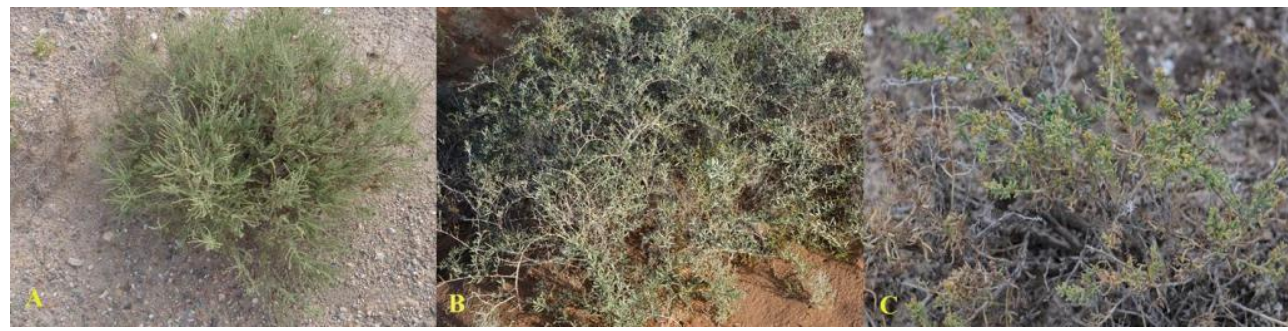

Figure 2. Pictures of three dominant desert plants in the middle reaches of Heihe River Basin. A: Reaumuria soongarica M., B: Nitraria sphaerocarpa M., C: Sympegma regelii B.

\subsection{Measurement of Hydraulic Conductivity and Functional Traits}

The measurement of hydraulic conductivity of desert plant organs was made using the high-pressure flowmeter (HPFM) (high-pressure flowmeter, HPFM-Gen3, Dynamax Inc., Houston, TX, USA). The pressure ratio per second was 3-7 kPa, and continuous injection was conducted on the plant organs to increase the pressure to approximately $500 \mathrm{kPa}$. According to the change relationship with time between steam flow rate and pressure, as well as the change relationship with time reflecting the plant internal resistance and hydraulic conductivity, the curve slope represented hydraulic conductivity, namely the ratio between the current velocity and pressure. The high-pressure flowmeter measuring plant hydraulic conductivity has an instantaneous and semi-stable flow velocity method, according to the comparison results of these two methods, the instantaneous method is more suitable for the determination of plants with lower hydraulic conductivity and the result is more accurate [22]. In addition, the instantaneous method is used to measure the hydraulic conductivity of plants under low pressure, and no water flow omission occurs due to branch damage. The method of determining the hydraulic conductivity of plants also has the advantages of being quick and convenient. As the water transport of desert plants is slower than crops, the instantaneous method was used to determine the hydraulic conductivity of desert plants.

\subsubsection{Measurement of Leaf and Stem Hydraulic Conductivity}

As a result of the degradation of the petiole of the three desert plants, the leaves grew directly on the branches, and the hydraulic conductivity of the leaves could not be directly measured. The study takes the method of Tyree et al. [22], the main principle of this method was based on the fact that the total resistance encountered when transporting water in the plant was equal to the resistances of the various parts, and the hydraulic conductivity of the various organs of plants was calculated according to the relationship between the resistance and hydraulic conductivity. First of all, five representative plants per species were selected in the habitats; three branches (including leaves) of sunny plants were taken in the early morning, about $10-15 \mathrm{~cm}$ in length, then were immediately sealed in black plastic bag packets and brought to the laboratory. During observation, the branches were vertically placed to simulate branch growth. The hydraulic conductivity of every branch, including leaves, was measured using the instantaneous method [22], and the hydraulic conductivity of the remaining branches was determined after the removal of the leaves. Finally, the hydraulic conductivity of the branches and leaves were respectively converted according to the resistance relationship [23]. The temperature in the laboratory at the time of measurement was $24.5^{\circ} \mathrm{C}$. The removed leaves were scanned by using a scanner LiDE110 (Canon scanner, CanoScan LiDE 110 Canon, Tokyo, Japan), and the leaf area (LA) was calculated using ImageJ software. The scanned leaves were placed in an envelope to dry in an $80{ }^{\circ} \mathrm{C}$ dryer to obtain the dry weight (LW).

The leaf hydraulic conductivity was expressed as leaf hydraulic conductivity per unit leaf area $\left(\mathrm{K}_{\mathrm{LA}}, \mathrm{K} / \mathrm{LA}, \mathrm{kg} \mathrm{s}^{-1} \mathrm{~cm}^{-2} \mathrm{MPa}^{-1}\right)$ and leaf hydraulic conductivity per unit leaf weight $\left(\mathrm{K}_{\mathrm{LW}}, \mathrm{K} / \mathrm{LW}\right.$, $\left.\mathrm{kg} \mathrm{s}^{-1} \mathrm{~g}^{-1} \mathrm{MPa}^{-1}\right)$, respectively. The stem hydraulic conductivity was expressed as stem hydraulic conductivity per unit leaf area $\left(\mathrm{K}_{\mathrm{SLA}}, \mathrm{K} / \mathrm{LA}, \mathrm{kg} \mathrm{s}^{-1} \mathrm{~cm}^{-2} \mathrm{MPa}^{-1}\right)$ and stem hydraulic conductivity per 
unit leaf weight $\left(\mathrm{K}_{\mathrm{SLW}}, \mathrm{K} / \mathrm{LW}, \mathrm{kg} \mathrm{s}^{-1} \mathrm{~g}^{-1} \mathrm{MPa}^{-1}\right)$, respectively. The ration of leaf dry weight and leaf area is specific leaf weight (SLM, $\mathrm{g} \mathrm{cm}^{-2}$ ), the reciprocal value is the specific leaf area (SLA, $\mathrm{cm}^{2} \mathrm{~g}^{-1}$ ).

\subsubsection{Measurement of Root System Hydraulic Conductivity}

In the determination of the hydraulic conductivity of the whole roots, the parts about $5 \mathrm{~cm}$ above ground for $R$. soongarica, $N$. sphaerocarpa, and S. regelii were cut with a blade and the hydraulic conductivity of the whole roots below the cutting point was measured. After digging the whole roots of the plants, they were returned to the laboratory in a black plastic bag with a shaded back, the soil residue of root surface was washed with water, and then part of the fine roots ( $<2 \mathrm{~mm}$ diameter) [24] was used to measure the hydraulic conductivity of the fine roots. Finally, all of the root system was stained with $0.5 \%$ methylene blue for $12 \mathrm{~h}$, and the scanner Lide110 was employed to scan the root system. The root system for measuring the hydraulic conductivity of the fine roots was scanned alone, and the root analysis software program WinRhizo was employed to determine the root length (RL, cm), root diameter $(\mathrm{RD}, \mathrm{cm})$, and root surface area $\left(\mathrm{RSA}, \mathrm{cm}^{2}\right)$, along with other morphological parameters. Finally, the root systems were placed into envelopes after scanning, and then dried in an $80^{\circ} \mathrm{C}$ baking oven until reaching a constant weight and determining the dry weight of the roots (RW, g). The ratio of root length to root weight was the specific root length (SRL, $\mathrm{cm} \mathrm{g}^{-1}$ ), and the ratio of root surface area to root weight was the specific root surface area (SRSA, $\mathrm{cm}^{2} \mathrm{~g}^{-1}$ ). The whole root hydraulic conductivity is expressed by root hydraulic conductivity per unit root weight $\left(\mathrm{K}_{\mathrm{RW}}, \mathrm{kg} \mathrm{s}^{-1} \mathrm{~g}^{-1} \mathrm{MPa}^{-1}\right)$ and the fine root hydraulic conductivity is expressed by root hydraulic conductivity per unit leaf length $\left(K_{\mathrm{RL}}, \mathrm{kg} \mathrm{s}^{-1} \mathrm{~cm}^{-1} \mathrm{MPa}^{-1}\right)$, root hydraulic conductivity per unit root weight $\left(\mathrm{K}_{\mathrm{RW}}, \mathrm{kg} \mathrm{s}^{-1} \mathrm{~g}^{-1}\right.$ $\left.\mathrm{MPa}^{-1}\right)$, and root hydraulic conductivity per unit root surface area $\left(K_{\mathrm{RSA}}, \mathrm{kg} \mathrm{s}^{-1} \mathrm{~cm}^{-2} \mathrm{MPa}^{-1}\right)$.

\subsection{Statistics Analysis}

The data were analyzed using the SPSS 19.0 statistical analysis software package (Statistical Product and Service Solutions, SPSS 19.0, Chicago, IL, USA.), and the correlation analysis and single factor analysis of variance were used. Origin 8.0 (OriginLab Corporation, OriginPro 8 SR0, Northampton, MA, USA) was used for the preparation of the figures.

\section{Results}

\subsection{Characteristics of Root and Leaf Traits of Three Desert Plants}

For the leaves, the SLW of R. soongarica was higher than those of N. sphaerocarpa and S. regelii, but there were no significant differences. In contrast, the SLA of $R$. soongarica was significantly lower than those of N. sphaerocarpa and S. regelii. For the fine roots of the plants, both the SRL and SRSA of the three plants demonstrated significant differences, and the SRL and SRSA of N. sphaerocarpa was the highest, followed by S. regelii, and the SRL and SRSA of $R$. soongarica were the lowest. Table 1 shows the leaf and fine root traits of the three desert plants.

\subsection{Characteristics of Hydraulic Conductivity in Different Organs of Desert Plants}

Hydraulic conductivity is one of the most commonly used and important parameters in hydraulic architecture characteristics. The results of the hydraulic conductivity of the three plants' different organs are shown in Figure 3. For leaf, the hydraulic conductivity of $S$. regelii were significantly lower than $R$. soongarica and N. sphaerocarpa. However, $\mathrm{K}_{\mathrm{LA}}$ and $\mathrm{K}_{\mathrm{LW}}$ of the three plants showed the opposite trend, with the lowest value of $R$. soongarica, $S$. regelii were the highest, and $N$. sphaerocarpa were moderate. There were significant differences in $\mathrm{K}_{\mathrm{LA}}$ and $\mathrm{K}_{\mathrm{LW}}$ of the three plants.

In the stems of the plants, the hydraulic conductivity of $R$. soongarica, N. sphaerocarpa, and S. regelii were significantly different, among which $R$. soongarica had the highest value $\left(6.55 \mathrm{~kg} \mathrm{~s}^{-1} \mathrm{MPa}^{-1}\right)$, followed by S. regelii $\left(4.09 \mathrm{~kg} \mathrm{~s}^{-1} \mathrm{MPa}^{-1}\right)$, and $N$. sphaerocarpa had the lowest value $\left(2.58 \mathrm{~kg} \mathrm{~s}^{-1} \mathrm{MPa}^{-1}\right)$. However, there were no significant differences in the $\mathrm{K}_{\mathrm{SLA}}$ and $\mathrm{K}_{\mathrm{SLW}}$ between $R$. soongarica and 
N. sphaerocarpa. The $\mathrm{K}_{\mathrm{SLA}}$ and $\mathrm{K}_{\mathrm{SLW}}$ of S. regelii were significantly higher than those of the other plants. The $\mathrm{K}_{\mathrm{SLA}}$ and $\mathrm{K}_{\mathrm{SLW}}$ tended to be a consistent trend among these three dominant desert plants (Figure 3).

Fine roots are important parts of plants for water absorption. The determination of hydraulic conductivity of fine roots can reflect the absorption capacity of plants on soil water. If the hydraulic conductivity of the fine roots is high, then the water absorption ability will be strong. The hydraulic conductivity of the fine roots, root length, and root surface area of the three plants showed a similar trend, in which there was no significant difference between $R$. soongarica and N. sphaerocarpa, which were higher than the $S$. regelii. The hydraulic conductivity of the fine roots, root length, and root surface area of $S$. regelii were lower than those of $R$. soongarica and $N$. sphaerocarpa. The hydraulic conductivity of root weight is different from the other three indicators, and the hydraulic conductivity of root weight of $N$. sphaerocarpa was significantly higher than that of $R$. soongarica, the hydraulic conductivity of root weight of the fine roots of $S$. regelii was the lowest.

\subsection{Correlation of Hydraulic Conductivity with Root and Leaf Traits in Desert Plants}

The functional traits of leaves and roots reflect the drought tolerance characteristics of plants, and there must be some connection between the hydraulic conductivity characteristics of plants and plant functional traits. Correlation analysis was performed on the hydraulic conductivity of different organs of the three desert plants and the trait indicators of the roots, stems, and leaves (Table 2), and the results showed that $\mathrm{K}_{\mathrm{LW}}, \mathrm{K}_{\mathrm{SLA}}$, and $\mathrm{K}_{\mathrm{SLW}}$ of $R$. soongarica, N. sphaerocarpa, and S. regelii had extremely significant positive correlations $(r=0.935, r=0.950, P<0.01)$. There were also the same positive correlations between $\mathrm{K}_{\mathrm{SLA}}$ and $\mathrm{K}_{\mathrm{SLW}}$ of stem $(r=0.988, P<0.01)$, as well as significant positive correlations between the $\mathrm{K}_{\mathrm{RW}}$ of the fine roots and the SRSA $(r=0.727, P<0.05)$. In addition, there was a significant negative correlation between the SLW of the plants and the SRL of the fine root, and a significant positive correlation with the RW, but no significant correlation with the diameter and length of the root system, indicating a positive correlation between the SLW and the density of the fine root. In other words, when the plants are under drought stress, it will increase the thickness of the leaves or the lignification of the fine roots to enhance its drought tolerance. The specific root length of the fine roots and specific root surface area also had very significant positive correlations.

Relative to the root cells and individual root hydraulic conductivity, the whole root hydraulic conductivity integrated the root morphology structure, metabolic activity, and characteristics of water channel proteins on the root cell plasma membranes, so that it could better reflect the whole plant's capacity of absorbing water [8]. The hydraulic conductivity of the whole root of $R$. soongarica and $N$. sphaerocarpa were $2.14 \times 10^{-4}$ and $1.86 \times 10^{-4} \mathrm{~kg} \mathrm{~s}^{-1} \mathrm{~g}^{-1} \mathrm{MPa}^{-1}$, and the differences between them were not significant, while the hydraulic conductivity of $S$. regelii was $0.27 \times 10^{-4} \mathrm{~kg} \mathrm{~s}^{-1} \mathrm{~g}^{-1} \mathrm{MPa}^{-1}$, which was significantly lower than that of $R$. soongarica and N. sphaerocarpa (Figure 4). 

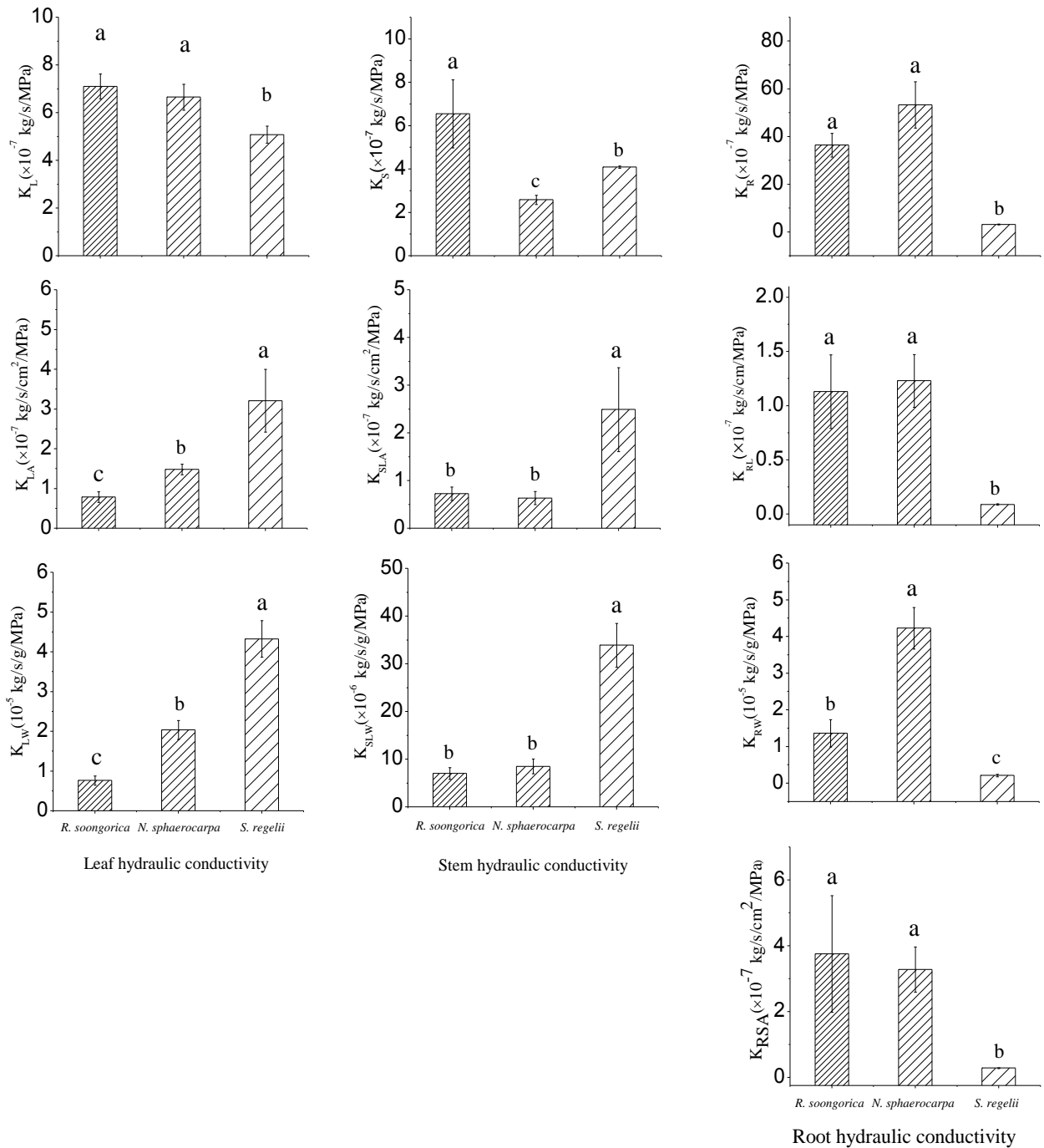

Figure 3. Hydraulic conductivity of different organs in R. soongorica, N. sphaerocarpa, and S. regelii. Different letters indicate significant differences between plants, $p<0.05$, and the same letters are not significantly different, $p>0.05$. $\mathrm{K}_{\mathrm{L}}$ : leaf hydraulic conductivity; $\mathrm{K}_{\mathrm{S}}$ : stem hydraulic conductivity; $\mathrm{K}_{\mathrm{R}}$ : root hydraulic conductivity; $\mathrm{K}_{\mathrm{LA}}$ : leaf area hydraulic conductivity; $\mathrm{K}_{\mathrm{SLA}}$ : specific leaf area hydraulic conductivity; $\mathrm{K}_{\mathrm{RL}}$ : root length hydraulic conductivity; $\mathrm{K}_{\mathrm{LW}}$ : leaf weight hydraulic conductivity; $\mathrm{K}_{\mathrm{SLW}}$ : specific leaf weight hydraulic conductivity; $\mathrm{K}_{\mathrm{RW}}$ : root weight hydraulic conductivity; $\mathrm{K}_{\mathrm{RSA}}$ : root surface area hydraulic conductivity.

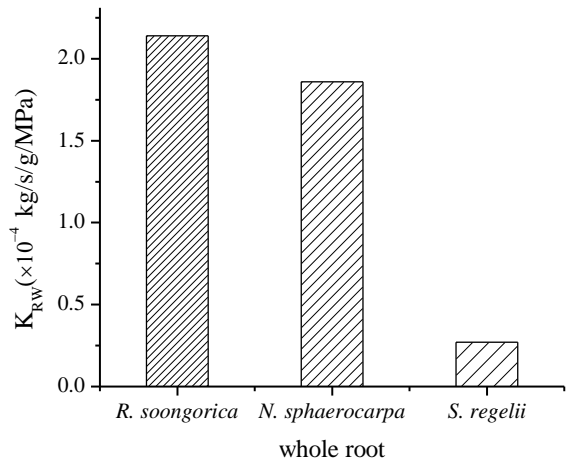

Figure 4. Whole root hydraulic conductivity of $R$. soongorica, N. sphaerocarpa, and S. regelii. 
Table 1. Fine root and leaf traits of three desert plants.

\begin{tabular}{|c|c|c|c|c|}
\hline \multirow{2}{*}{ Plant Species } & \multicolumn{2}{|c|}{ Leaf } & \multicolumn{2}{|c|}{ Fine Root } \\
\hline & $\operatorname{SLW}\left(\mathrm{g} \mathrm{cm}^{-2}\right)$ & $\operatorname{SLA}\left(\mathrm{cm}^{2} \mathrm{~g}^{-1}\right)$ & SRL $\left(\mathrm{cm} \mathrm{g}^{-1}\right)$ & SRSA $\left(\mathrm{cm}^{2} \mathrm{~g}^{-1}\right)$ \\
\hline R. soongorica & $0.010 \pm 0.00 \mathrm{a}$ & $97.35 \pm 3.34 b$ & $121.55 \pm 16.31 \mathrm{c}$ & $51.04 \pm 3.65 c$ \\
\hline N. sphaerocarpa & $0.007 \pm 0.00 \mathrm{a}$ & $137.02 \pm 7.33 a$ & $364.15 \pm 60.28 \mathrm{a}$ & $138.13 \pm 25.44 a$ \\
\hline S. regelii & $0.007 \pm 0.00 \mathrm{a}$ & $142.03 \pm 9.00 \mathrm{a}$ & $239.23 \pm 40.84 b$ & $74.82 \pm 12.74 b$ \\
\hline
\end{tabular}

Note: different letters in the same column indicate significant differences between different plants, $p<0.05$, and the same letters in the same column are not significantly different, $p>0.05$. SLW: specific leaf weight; SLA: specific leaf area; SRL: specific root length; SRSA: specific root surface area.

Table 2. Correlation analysis between the hydraulic conductance of different organs and plant traits.

\begin{tabular}{|c|c|c|c|c|c|c|c|c|c|c|c|}
\hline Plant Traits & $\mathrm{K}_{\mathrm{LW}}$ & $\mathrm{K}_{\mathrm{SLA}}$ & $\mathrm{K}_{\mathrm{SLW}}$ & SLW & SLA & $\mathbf{K}_{\mathrm{RW}}$ & RD & RL & RSA & RW & SRL \\
\hline $\mathrm{K}_{\mathrm{SLA}}$ & $0.935^{* *}$ & & & & & & & & & & \\
\hline $\mathrm{K}_{\mathrm{SLW}}$ & $0.950 * *$ & $0.988^{* *}$ & & & & & & & & & \\
\hline SLW & -0.444 & -0.182 & -0.313 & & & & & & & & \\
\hline $\mathrm{K}_{\mathrm{RW}}$ & -0.342 & -0.516 & -0.528 & -0.097 & 0.054 & & & & & & \\
\hline RD & -0.375 & -0.458 & -0.436 & -0.059 & 0.005 & 0.334 & & & & & \\
\hline RL & 0.247 & 0.024 & 0.020 & -0.234 & 0.153 & 0.280 & 0.597 & & & & \\
\hline SRL & 0.156 & -0.14 & -0.057 & $-0.735^{*}$ & $0.715^{*}$ & 0.582 & 0.222 & 0.382 & 0.279 & $-0.776^{*}$ & \\
\hline SRSA & -0.023 & -0.292 & -0.230 & -0.582 & 0.559 & $0.727 *$ & 0.34 & 0.366 & 0.35 & $-0.696^{*}$ & $0.966^{* *}$ \\
\hline
\end{tabular}

** Correlation is significant at the 0.01 level. * Correlation is significant at the 0.05 level. $\mathrm{K}_{\mathrm{LW}}$ : leaf weight hydraulic conductivity; $\mathrm{K}_{\mathrm{SLA}}$ : specific leaf area hydraulic conductivity; $\mathrm{K}_{\mathrm{SLW}}$ : specific leaf weight hydraulic conductivity; SLW: specific leaf weight; SLA: specific leaf area; $\mathrm{K}_{\mathrm{RW}}$ : root weight hydraulic conductivity; RD: root diameter; RL: root length; RSA: root surface area; RW: root weight; SRL: specific root length; SRSA: specific root surface area.

\section{Discussion and Conclusions}

The study of plant water eco-physiology characteristics is the basis for research on the drought resistance of whole plants. In the soil-plant-atmosphere continuum (SPAC) system, the plants ensure the continuity of water transfer through the dynamic balance of water absorption, dissipation, and utilisation [25]. The transportation of water will encounter various obstacles, in which the resistance of water flow encountered in the xylem sap was small, while the resistance encountered in water transportation was mainly concentrated in the aspects of entering plants through the roots and escaping from the pores of the plants. In this study, the hydraulic conductivity of different organs of three desert plants was determined to investigate how plants adjust the hydraulic structure to adapt to the arid environment strategy. The study results showed that the hydraulic conductivity of leaves and stems of $R$. soongarica and $N$. sphaerocarpa were significantly lower than that of $S$. regelii, but their hydraulic conductivity of fine roots and the whole root were higher than that of $S$. regelii (Figure 3 ), indicating that $R$. soongarica and $N$. sphaerocarpa have strong absorption capacities and a low water loss rate of leaves, which can enable the plant to maintain the continuity of water transportation under soil drought stress, and avoid the occurrence of cavitation and embolism. This is a strategy for adaptation to an arid environment for $R$. soongarica and N. sphaerocarpa, however, S. regelii effectively increased water use efficiency (WUE) through higher leaf hydraulic conductivity and lower root hydraulic conductivity (Figure 4), which is consistent with the results of the study of these three desert plants' WUE reflected by stable carbon isotope. This is because the stable carbon isotope composition $\left(\delta^{13} \mathrm{C}\right)$ reflects the long-term WUE of plants. Studies have shown that $\delta^{13} \mathrm{C}$ of $R$. soongarica, N. sphaerocarpa, and S. regelii were $-25.64,-26.19$, and $-24.66 \%$, respectively, the WUE of S. regelii was higher than those of R. soongarica and N. sphaerocarpa [26]. The results demonstrated that the R. soongarica and $N$. sphaerocarpa preserved their water content through the strong leaf absorption capacity of soil water and low water dispersion rates of leaves to adapt to the harsher arid habitat, which is more drought tolerance than S. regelii. 
Water is a limiting factor for plant growth in arid areas. In order to adapt to arid environments, plants formed multiple adaptation mechanisms in terms of morphology and physiology to resist the drought stress environment of the outside world, including plant morphology structure, growth rate, water use efficiency, antioxidant system, and developed root system. A large number of studies have indicated that the morphological structure of the leaves was closely related to the drought resistance of crops, and the leaf thickness, area, and specific leaf weight were the important indexes of evaluating the drought resistance of crops [14-16]. Under water stress, the plants tended to form leaves with larger thickness and smaller area, and the dry weight of the unit leaf area increased [27]. The analysis based on the characteristics of the leaves of 2548 of plants from 175 sampling points throughout the world by Wright et al. [13] demonstrated that the SLA increased with the decrease of rainfall and the increase of light radiation. Li et al. [9] investigated the morphologies of the leaves of the peanut varieties with different drought resistances, and the results demonstrated that the drought stress decreased the leaf area and increased the specific leaf weight. In the present study, there was a negative correlation between the hydraulic conductivity of stems and leaves of desert plants and specific leaf weight (Table 2), indicating that in plants with strong drought resistance, the hydraulic conductivity of the stems and leaves was low. The main mechanism is that the increase of the specific leaf weight and leaf thickness lengthen the path of plant water loss, increase resistance during water transport, reduce leaf hydraulic conductivity, and help the plant to adapt to the desert environment, this result consistent with the study by Sinclair et al [6]; the stronger the drought resistance, the lower the leaf hydraulic conductivity.

The root system is the organ that is first aware of soil drought, and its morphological characteristics, such as root length and root weight, are closely related to the drought resistance of plants [26]. It has been observed that the whole root hydraulic conductivity of maize was significantly positively correlated with drought resistance of maize varieties [8]. The root diameter and cortical thickness of the winter wheat with strong drought resistance were large, as was the radial resistance to water flow, and the root hydraulic conductivity was low, that is, there were significant negative correlations between the root hydraulic conductivity, root diameter, and cortical thickness [5]. Rieger et al. [28] investigated two xylophytas and three herbages with different anatomical structures, and observed that there were significant negative correlations between the root hydraulic conductivity, root diameter, and cortical thickness, suggesting that the plants with thin roots or thin cortical roots had high hydraulic conductivity. In the present study, the hydraulic conductivity of the fine root weight $\left(\mathrm{K}_{\mathrm{RW}}\right)$ was positively correlated with the fine root diameter, which is not consistent with the results of Rieger et al. [28]. The mechanism may be as follows: under the condition of drought stress, in order to avoid the mechanical damage of soil particles and burn of the high temperature of desert environment leading to the increase of cortex thickness for the fine roots of desert plants, the thickness of the roots increases. It is also shown that the effect of cortical thickness on root hydraulic conductance are larger than that of the roots diameter. Moreover, the correlation analysis in Table 2 shows that the hydraulic conductivity of the fine root weight $\left(\mathrm{K}_{\mathrm{RW}}\right)$ was positively correlated with root length, surface area, and specific root length and specific surface area. Its correlation with the specific surface area was significant, mainly due to the fact that long fine root system, large surface area, long specific root length, high specific surface area, increase of contacting with soil surface, and improvement of water absorption efficiency are conducive to absorbing significant amounts water and enhancing root hydraulic conductivity and drought resistance. This is different from Yang et al. [5] in the study of the relationship between the hydraulic conductivity and drought resistance of different winter wheat roots. Winter wheat enhances its drought resistance by reducing the hydraulic conductivity of roots; however, these three desert shrubs have opposite trends, mainly due to the more partial branching of the shrub on the aboveground, during the transportation of plant water from the roots to the leaves, more resistance will be encountered. In order to ensure the water supply, the hydraulic conductivity of the shrub roots will increase. This result may be related to their life forms. $R$. soongarica 
and N. sphaerocarpa are shrubs, while S. regelii is a semi-shrub. The degree of lignification of shrubs is high and the water transfer efficiency of the wood catheter is high.

Author Contributions: Methodology, S.L. and P.S.; Formal Analysis, H.Z.; Investigation, S.L., Z.Z., R.S., and W.G.; Resources, P.S.; Data Curation, S.L.; Writing-Original Draft Preparation, S.L. and H.Z.; Project Administration, P.S.

Funding: This research was funded by National Natural Science Foundation of China grant number 41261013, Open fund projects of Research Center of Water Resources and Ecological Environment of Poyang Lake, the Ministry of Water Resources of the People's Republic of China, and the Study on spatial heterogeneity of Vitex trifolia nebkhas in Poyang Lake sand grant number ZXKT201510, Gansu Provincial Key Research and Development Program grant number 18YF1FA066, Lanzhou Science and Technology Development Program grant number 2017-4-94.

Acknowledgments: We are grateful to the anonymous reviewers and editor for their constructive comments on the manuscript.

Conflicts of Interest: The authors declare that there is no conflict of interest.

\section{References}

1. Noy-Meir, I. Desert ecosystems: environment and producers. Annu. Rev. Ecol. Syst. 1973, 4, 25-51. [CrossRef]

2. Steudle, E. The cohesion-tension mechanism and the acquisition of water by plant roots. Annu. Rev. Plant Physiol. Plant Mol. Biol. 2001, 53, 847-875. [CrossRef] [PubMed]

3. Li, X.R.; Tan, H.J.; He, M.Z.; Wang, X.P.; Li, X.J. Patterns of shrub species richness and abundance in relation to environmental factors on the Alxa Plateau: Prerequisites for conserving shrub diversity in extreme arid desert regions. Sci China-Earth Sci. 2009, 52, 669-680. [CrossRef]

4. Martre, P.; North, G.B.; Nobel, P.S. Hydraulic conductance and mercury-sensitive water transport for roots of Opuntia acanthocarpa in relation to soil drying and rewetting. Plant Physiol. 2001, 126, 352-362. [CrossRef] [PubMed]

5. Yang, X.Q.; Zhang, S.Q.; Liu, X.F.; Mu, Z.X. Relationship between root s hydraulic conductivity and root anatomy of winter wheat (Triticum aestivum). J. Northwest A F Univ. 2007, 35, 160-164.

6. Sinclair, T.R.; Zwieniecki, M.A.; Holbrook, N.M. Low leaf hydraulic conductance associated with drought tolerance in soybean. Physiol. Plant. 2010, 132, 446-451. [CrossRef] [PubMed]

7. Zhai, H.B.; Li, J.Y.; Jiang, J.P. Effect of drought stress on hydraulic architecture characteristics of Pinus tabulaeformis and Platycladus orientalis seedlings. J. Beijing For. Univ. 2002, 24, 45-49.

8. Mu, Z.X.; Zhang, S.Q.; Liang, A.H.; Liang, Z.S. Relationship between maize root hydraulic conductivity and drought resistance. Acta Agron. Sin. 2005, 31, 203-208.

9. Li, G.H.; Zhang, K.; Liu, F.Z.; Liu, D.D.; Wan, Y.S. Morphological and physiological traits of leaf in different drought resistant peanut cultivars. Sci. Agric. Sin. 2014, 47, 644-654.

10. Fernández, R.J.; Wang, M.; Reynolds, J.F. Do morphological changes mediate plant responses to water stress? A steady-state experiment with two C4 grasses. New Phytol. 2010, 155, 79-88.

11. He, W.M.; Zhang, X.S. Responses of an evergreen shrub Sabina vulgaris to soil water and nutrient shortages in the semi-arid Mu Us Sandland in China. J Arid Environ. 2003, 53, 307-316. [CrossRef]

12. Zheng, S.X.; Shangguan, Z.P. Photosynthetic characteristics and their relationships with leaf nitrogen content and leaf mass per area in different plant functional types. Acta Ecol. Sin. 2007, 27, 171-181.

13. Wright, I.J.; Reich, P.B.; Westoby, M. The worldwide leaf economics spectrum. Nature. 2004, 428, 821-827. [CrossRef] [PubMed]

14. Painawadee, M.; Jogloy, S.; Kesmala, T.; Akkasaeng, C.; Patanothai, A. Identification of Traits Related to Drought Resistance in Peanut (Arachis hypogaea L.). Asian J. Plant Sci. 2009, 8, 120-128.

15. Kulkarni, M.; Schneider, B.; Raveh, E. Leaf anatomical characteristics and physiological responses to short-term drought in Ziziphus mauritiana (Lamk.). Sci. Hortic Amst. 2010, 124, 316-322. [CrossRef]

16. Singh, S.K.; Reddy, K.R. Regulation of photosynthesis, fluorescence, stomatal conductance and water-use efficiency of cowpea (Vigna unguiculata [L.] Walp.) under drought. J Photochem. Photobiol. B. Biol. 2011, 105, 40-50. [CrossRef] [PubMed]

17. Eissenstat, D.M. On the relationship between specific root length and the rate of root proliferation: A field study using citrus rootstocks. New Phytol. 1991, 118, 63-68. [CrossRef] 
18. Shan, L.S. Studies on Morphology and Function of Root of Typical Desert Plant and Its Drought-Resistant Physiology Characteristics on Northwest China. Ph.D. Thesis, Gansu Agricultural University, Lanzhou, China, June 2013.

19. Cortina, J.; Green, J.J.; Baddeley, J.A.; Watson, C.A. Root morphology and water transport of Pistacia lentiscus seedlings under contrasting water supply: A test of the pipe stem theory. Environ. Exp. Bot. 2008, 62, 343-350. [CrossRef]

20. Running, S.W. Field estimates of root and xylem resistance in Pinus contorta using root excision. J. Exp. Bot. 1980, 31, 555-569. [CrossRef]

21. Su, P.X.; Liu, X.M.; Zhang, L.X.; Zhao, A.F.; Li, W.R.; Chen, H.S. Comparison of $\delta 13 \mathrm{C}$ values and gas exchange of assimilating shoots of desert plants Haloxylon ammodendron and Calligonum mongolicum with other plants. Isr. J. Plant. Sci. 2004, 52, 87-97. [CrossRef]

22. Tyree, M.T.; Sinclair B, Lu. P.; Granier, A. Whole shoot hydraulic resistance in Quercus species measured with a new high-pressure flowmeter. Ann. For. Sci. 1993, 50, 417-423. [CrossRef]

23. Tyree, M.T.; Patiño, S.; Bennink, J.; Alexander, J. Dynamic measurements of roots hydraulic conductance using a high-pressure flowmeter in the laboratory and field. J. Exp. Bot. 1995, 46, 83-94. [CrossRef]

24. Wilcox, C.S.; Ferguson, J.W.; Fernandez, G.C.J.; Nowak, R.S. Fine root growth dynamics of four Mojave Desert shrubs as related to soil moisture and microsite. J. Arid Environ. 2004, 56, 129-148. [CrossRef]

25. Turner, N.C. Further progress in crop water relations. Adv. Agron. 1997, 58, 293-338.

26. Zhang, H.N.; Su, P.X.; Li, S.J.; Zhou, Z.J.; Xie, T.T.; Zhao, Q.F. Indicative effect of the anatomical structure of plant photosynthetic organ on WUE in desert region. Acta Agron. Sin. 2013, 33, 4909-4918. [CrossRef]

27. Flexas, J.; Medrano, H. Drought inhibition of photosynthesis in C3 plants: Stomatal and non-stomatal limitations revisited. Ann. Bot-London. 2002, 89, 183-189. [CrossRef]

28. Rieger, M.; Litvin, P. Root system hydraulic conductivity in species with contrasting root anatomy. J. Exp. Bot. 1999, 50, 201-209. [CrossRef]

(C) 2018 by the authors. Licensee MDPI, Basel, Switzerland. This article is an open access article distributed under the terms and conditions of the Creative Commons Attribution (CC BY) license (http:/ / creativecommons.org/licenses/by/4.0/). 